\section{ORIGINAL RESEARCH}

K. Aydin

A. Ucok

S. Cakir

\title{
Quantitative Proton MR Spectroscopy Findings in the Corpus Callosum of Patients with Schizophrenia Suggest Callosal Disconnection
}

\begin{abstract}
BACKGROUND AND PURPOSE: The callosal disconnectivity theory was previously proposed to explain the pathophysiology of schizophrenia. The goal of this study was to investigate the metabolic integrity of the corpus callosum in patients with schizophrenia by proton MR spectroscopy.
\end{abstract}

\begin{abstract}
MATERIALS AND METHODS: Twelve first-episode and 16 chronic patients meeting the Diagnostic and Statistical Manual of Mental Disorders (DSM-IV) criteria for schizophrenia and 28 age- and sex-matched control subjects were enrolled in the study. We measured the absolute concentrations of neurometabolites and $\mathrm{T} 2$ relaxation times of tissue water $\left(\mathrm{T} 2_{\mathrm{B}}\right)$ in the genu of the corpus callosum by using the internal water-reference method. The severity of symptoms in patients was rated by means of psychopathology scales. Differences in neurometabolite concentrations and $\mathrm{T} 2_{\mathrm{B}}$ values between the patients and control subjects were assessed. We also investigated the correlation of metabolite concentrations with the severity of symptoms.
\end{abstract}

RESULTS: $N$-acetylaspartate (NAA) concentrations were significantly lower in the first-episode as well as in chronic patients, compared with respective control subjects $(P<.001)$. NAA concentrations in the first-episode and chronic patient groups were negatively correlated with both the Brief Psychiatry Rating Scale and the Scale for Assessment of Negative Symptoms scores $(P<.001)$. There was a significant negative correlation between the NAA concentrations and the Scale for Assessment of Positive Symptoms scores in all patients $(P=.028)$. $T 2_{\mathrm{B}}$ values were significantly higher in the patients, compared with the control subjects $(P<.001)$.

CONCLUSION: Decreased NAA concentration in the corpus callosum correlates with psychopathology in schizophrenia. This finding, together with prolonged $\mathrm{T} 2_{\mathrm{B}}$ values of the corpus callosum, supports the previously proposed callosal disconnection theory concerning the pathophysiology of schizophrenia.

$T^{1}$ he idea that schizophrenia might be a disorder of functional disconnection between the various regions of brain was first proposed by Wernicke in $1906 .{ }^{1}$ More recently, the disconnectivity theory has re-emerged in schizophrenia research. ${ }^{2-4}$ Today, there is increasing evidence pointing to the possibility of an abnormal cortical connectivity in the pathophysiology of schizophrenia. Diffusion tensor imaging (DTI) studies have demonstrated the compromised cerebral white matter tracts in patients with schizophrenia. ${ }^{5-8}$ Altered magnetization transfer (MT) ratios in frontotemporal white matter tracts and the genu of the corpus callosum, which might indicate either an axonal or a myelin-related pathology in schizophrenia, were found in patients with schizophrenia in MT imaging studies. ${ }^{9,10}$ Supporting the results of these structural imaging studies, the genetic studies revealed the altered expression of myelin-related genes, suggesting a disruption in oligodendrocyte function in schizophrenia. ${ }^{11,12}$

Crow $^{4}$ further specified the disconnectivity theory and proposed that schizophrenia might be a disorder of transcallosal misconnection. The corpus callosum is the major interhemispheric white matter tract, which plays very important roles in cognitive processes such as language, memory, and sensory-motor integration. ${ }^{13}$ Interhemispheric transmission

Received December 21, 2006; accepted after revision April 17, 2007

From the Departments of Neuroradiology (K.A.) and Psychiatry (A.U., S.C.), MR Research Unit, İstanbul Medical School, İstanbul University, Capa, İstanbul, Turkey.

Please address correspondence to Kubilay Aydin, MD, Adnan saygun caddesi. M.Salihrustu bey sokak, Ulus Konaklari No:8/12, Ulus, Istanbul, Turkey; e-mail: dr.aydink@superonline. com

DOI 10.3174/ajnr.A0691 of information, which allows the functional lateralization of cerebral hemispheres, decreases in schizophrenia. ${ }^{14,15}$ Functional and structural asymmetry in cerebral hemispheres in patients with schizophrenia suggests the possibility of altered interhemispheric connectivity. There are several morphometric studies revealing controversial results on the size and shape differences of the corpus callosum in schizophrenia. ${ }^{16-20}$ In a meta-analysis, Woodruff et $\mathrm{al}^{21}$ reported a small but significant decrease in the midsagittal area of the corpus callosum. Studies investigating shape differences in the corpus callosum showed that patients with schizophrenia had a more curved corpus callosum. ${ }^{22-24}$ In addition, the corpus callosum was one of the common locations showing a reduced diffusion anisotropy and MT ratio in previous DTI and MT imaging studies investigating white matter integrity in patients with schizophrenia. ${ }^{5-10}$ Moreover, the structural MR imaging studies conducted in patients with schizophrenia revealed altered signal-intensity changes and decreased attenuation in the corpus callosum. ${ }^{25,26}$

Proton MR spectroscopy ( ${ }^{1} \mathrm{H}-\mathrm{MR}$ spectroscopy) is a noninvasive method to investigate neurochemical changes in various pathologic and physiologic conditions. ${ }^{1} \mathrm{H}-\mathrm{MR}$ spectroscopy can demonstrate subtle neuroaxonal dysfunction, even in normal-appearing cerebral tissue on conventional MR imaging and DTI. ${ }^{27}$ The goal of this study was to investigate the metabolic integrity of the corpus callosum in patients with schizophrenia and to test the "callosal disconnectivity theory" by using ${ }^{1} \mathrm{H}-\mathrm{MR}$ spectroscopy. We hypothesized that microstructural abnormalities in the corpus callosum of patients with schizophrenia might cause axonal dysfunction and lead 
Table 1: Clinical and demographic characteristics of the patients and control subjects*

\begin{tabular}{|c|c|c|c|c|c|c|}
\hline & \multicolumn{2}{|c|}{ FE Group } & \multicolumn{2}{|c|}{ Chronic Group } & \multicolumn{2}{|c|}{ Combined Group } \\
\hline & $\begin{array}{l}\text { FE Patients } \\
(n=12)\end{array}$ & $\begin{array}{l}\text { Controls } \\
(n=14)\end{array}$ & $\begin{array}{l}\text { Chronic } \\
\text { Patients } \\
(n=16)\end{array}$ & $\begin{array}{l}\text { Controls } \\
(n=14)\end{array}$ & $\begin{array}{l}\text { All Patients } \\
(n=28)\end{array}$ & $\begin{array}{c}\text { All Controls } \\
(n=28)\end{array}$ \\
\hline Age (y) & $25.50 \pm 5.76$ & $25.16 \pm 5.35$ & $29.31 \pm 11.41$ & $28.93 \pm 10.24$ & $27.65 \pm 9.46$ & $27.32 \pm 8.58$ \\
\hline Male/Female & $8 / 4$ & $9 / 5$ & $11 / 5$ & $9 / 5$ & $19 / 9$ & $18 / 10$ \\
\hline Education (y) & $10.33 \pm 4.47$ & $10.33 \pm 3.89$ & $11.00 \pm 3.65$ & $11.00 \pm 3.40$ & $10.71 \pm 3.96$ & $10.71 \pm 3.56$ \\
\hline Age at onset (y) & $24.83 \pm 5.30$ & & $22.37 \pm 8.72$ & & $23.35 \pm 7.13$ & \\
\hline No. of hospitalizations & - & & $4.30 \pm 3.90$ & & - & \\
\hline DUP (months) & $11.20 \pm 10.20$ & & - & & - & \\
\hline Duration of illness (months) & - & & $83.25 \pm 68.65$ & & - & \\
\hline \multicolumn{7}{|l|}{ Psychopathology scores } \\
\hline BPRS & $58.75 \pm 8.60$ & & $67.56 \pm 11.18$ & & $63.92 \pm 10.96$ & \\
\hline SANS & $40.00 \pm 17.62$ & & $50.37 \pm 26.93$ & & $45.92 \pm 23.60$ & \\
\hline SAPS & $36.58 \pm 17.11$ & & $43.87 \pm 15.89$ & & $40.75 \pm 16.52$ & \\
\hline
\end{tabular}

Note:-FE indicates first-episode; -, data not available.; DUP, duration of untreated psychosis; BPRS, Brief Psychiatric Rating Scale; SANS, Scale for the Assessment of Negative Symptoms; SAPS, Scale for the Assessment of Positive Symptoms.

${ }^{*}$ Data are given as mean \pm SDs except where indicated.

to changes in neurometabolite concentrations, which could be detected by quantitative ${ }^{1} \mathrm{H}-\mathrm{MR}$ spectroscopy. We sought to measure the absolute concentrations of major neurometabolites and $\mathrm{T} 2$ relaxation times of tissue water $\left(\mathrm{T} 2_{\mathrm{B}}\right)$ in the corpus callosum of patients with schizophrenia. Additionally, we investigated the relationship of neurometabolite concentrations with $\mathrm{T} 2_{\mathrm{B}}$ values and the severity of symptoms. We studied the first-episode and relapsing chronic patients in acute phases of illness.

\section{Methods}

\section{Subjects}

We studied 28 inpatients (19 men and 9 women) with a diagnosis of schizophrenia after Structured Clinical Interviews for DSM-IV Axis I Disorders (SCID) data. ${ }^{28}$ Twelve of the patients ( 8 men and 4 women) were in the first episode of illness, and the remaining 16 (11 men and 5 women) were chronic patients presenting in the acute phase of illness (Table 1). A patient was accepted in his/her first psychotic episode when a previous diagnosis of possible psychosis, antipsychotic treatment, or inpatient care was ruled out. The mean \pm SD duration of untreated psychosis (DUP) was $11.20 \pm 10.20$ months in the patients in the first episode. Chronic illness was defined as an interval of illness that had lasted at least 3 years following the diagnosis of schizophrenia. Diagnosis of schizophrenia in first-episode patients was confirmed through a re-interview by using the SCID data on the sixth month following their discharge.

Although 10 of the first-episode patients were drug-naive at admission, only 2 were drug-naive at the time the ${ }^{1} \mathrm{H}$-MR spectroscopy examinations were performed. Although 8 of the first-episode patients were receiving risperidone (mean dose, $3.9 \mathrm{mg} / \mathrm{day}$ ), 2 of them were receiving olanzapine (mean dose, $12.5 \mathrm{mg}$ /day). The mean interval between the admissions and ${ }^{1} \mathrm{H}-\mathrm{MR}$ spectroscopy examinations was 7.8 days in first-episode patients. On the other hand, all of the chronic patients were taking antipsychotic drugs, both at admission and at the time the ${ }^{1} \mathrm{H}-\mathrm{MR}$ spectroscopy examinations were performed. Four patients were taking risperidone (mean dose, $5.5 \mathrm{mg} /$ day), 3 patients were taking quetiapine ( $600 \mathrm{mg}$ /day), 2 patients were taking olanzapine ( $12.5 \mathrm{mg} /$ day), and 5 patients were taking different types of antipsychotics (mean haloperidol-equivalent dose was 12.5 $\mathrm{mg}$ /day).

Twenty-eight age- and sex-matched volunteer subjects (14 con- trols for each patient group) were enrolled in the study as a control group. Each patient group (first episode and chronic) had equal education levels with its respective control group $(P>.05)$. The control subjects underwent medical, neurologic, and psychiatric (by using the Structured Clinical Interview for DSM-III-R-Non-Patient Edition by experienced interviewers) evaluation. Patients having any organic disorder, causing psychosis or cognitive impairment, were excluded from the study. Exclusion criteria for the patients and control subjects also included any contraindication for MR imaging, alcohol, or drug abuse; and any history of neurodegenerative disease, seizure, central nervous system infection, cerebrovascular disease, diabetes mellitus, and head trauma causing loss of consciousness that lasted more than 30 minutes or that required hospitalization. All the patients and control subjects were right-handed (Edinburgh Handedness Inventory). Written informed consent was obtained from 25 patients whose clinical states were stable enough to have a level of factual understanding of research consent forms ${ }^{29}$ and from all of the control subjects. Informed consent was taken from legal representatives of 3 patients whose clinical states were insufficient. The study was approved by the local Human Subject Committee.

\section{Clinical Assessment}

The psychopathologic state of patients was evaluated through the Brief Psychiatric Rating Scale (BPRS), the Scale for the Assessment of Positive Symptoms (SAPS), and the Scale for the Assessment of Negative Symptoms (SANS). ${ }^{30-32}$ All measures were collected by 2 trained raters. Inter-rater reliabilities for BPRS, SANS, and SAPS scores were acceptable ( $r=0.78, r=0.76$, and $r=0.83$, respectively). Clinical assessments, MR imaging, and ${ }^{1} \mathrm{H}-\mathrm{MR}$ spectroscopy examinations were performed within the same week.

\section{Cranial MR Imaging}

All patients underwent conventional cranial MR imaging and ${ }^{1} \mathrm{H}-\mathrm{MR}$ spectroscopy examinations on a $1.5 \mathrm{~T}$ superconducting whole-body MR imaging scanner and spectroscopic system (Symphony Maestro; Siemens, Erlangen, Germany) by using a standard quadrature head coil. Cranial MR images were acquired to position the MR spectroscopy volume of interest (voxel) and to identify any cerebral pathology defined in the exclusion criteria. MR images included the following: 1) axial fast spin-echo (SE) T2-weighted images $(\mathrm{TR}=5790 \mathrm{~ms}, \mathrm{TE}=$ $103 \mathrm{~ms}, \mathrm{NEX}=2$, echo-train length $=16$, matrix $=368 \times 512$, 

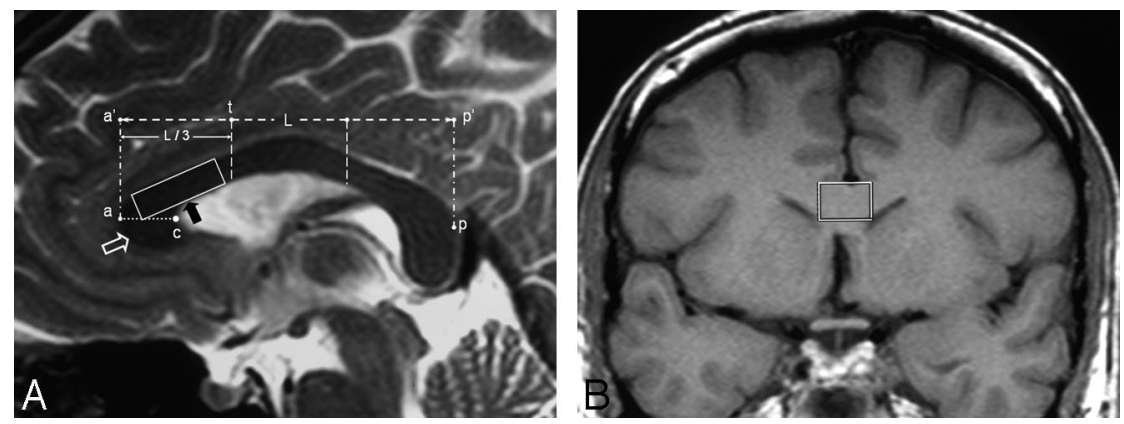

Fig 1. $A$ and $B, M R$ images showing the MR spectroscopy voxel placement. $A$, Midline sagittal T2-weighted MR image (TR/TE/NEX, 6790/103 ms/4) of a firstepisode patient shows the ${ }^{1} \mathrm{H}-\mathrm{MR}$ spectroscopic voxe placement. The maximal anteroposterior length (L) of the corpus callosum is identified (between points a' and $\left.p^{\prime}\right)$. The line drawn perpendicular to the $a^{\prime} p^{\prime}$ line at the anterior one-third point (point t) constitutes the posterior border of posterior genu region (separates the posterior genu from anterior midbody region). The horizontal line (line ac) drawn from the most anterior point of the corpus callosum (point a) to the "crook" of the genu (point c) separates the superior genu above and the inferior genu (open white arrow) below. The ${ }^{1} \mathrm{H}-\mathrm{MR}$ spectroscopic voxel (black arrow) is placed into the superior and posterior genu of the corpus callosum. B, Coronal T1-weighted MR image (TR/TE/NEX, 530/30 ms/2) demonstrates the voxel placement into the genu of the corpus callosum.

section thickness $=5 \mathrm{~mm}$, intersection distance $=1.2 \mathrm{~mm}$ ); 2 ) coronal SE T1-weighted images $(\mathrm{TR}=530 \mathrm{~ms}, \mathrm{TE}=30 \mathrm{~ms}, \mathrm{NEX}=2$, matrix $=196 \times 256$, section thickness $=3 \mathrm{~mm}$, intersection distance $=1 \mathrm{~mm})$; and 3) sagittal fast SE T2-weighted images $(\mathrm{TR}=$ $5790 \mathrm{~ms}, \mathrm{TE}=103 \mathrm{~ms}, \mathrm{NEX}=4$, echo-train length $=16$, matrix $=$ $196 \times 256$, section thickness $=3 \mathrm{~mm}$, intersection distance $=1 \mathrm{~mm}$ ).

\section{${ }^{1}$ H-MR Spectroscopy: Data Acquisition and Signal- Intensity Processing}

Single-voxel ${ }^{1} \mathrm{H}-\mathrm{MR}$ spectroscopy examinations of the patients and control subjects were conducted in the same session with conventional cranial MR imaging. On sagittal images, the corpus callosum was divided into subregions as described by Witelson ${ }^{33}$ and Highley et $\mathrm{al}^{34}$ (Fig 1A). Voxels were placed into the superior and posterior genu of the corpus callosum by excluding CSF around the corpus callosum (Fig 1B). The localization of both water-suppressed and unsuppressed proton spectra were acquired by applying a stimulated echo acquisition mode (STEAM, TR $=3.5$ seconds) sequence. Water suppression was performed with 3 chemical shift selective saturation pulses at the water resonance. The number of acquisitions for watersuppressed and unsuppressed spectra was 246 and 16, respectively. T2 values of metabolites and tissue water had to be calculated to correct signal-intensity decays caused by T2 (transverse) relaxations. Therefore, we obtained proton spectra with TE values of 30, 38, 48, 65, 84, 135 , and $300 \mathrm{~ms}$ with water suppression. TE values for water-unsuppressed spectra were $30,48,84,135,300,470$, and $800 \mathrm{~ms}$. Because T1 (longitudinal) relaxation does not affect the metabolite concentrations measured with TR values above 3 seconds at $1.5 \mathrm{~T}$, a TR value of 3.5 seconds, without $\mathrm{T} 1$ correction, was used. Spectral postprocessing included zero filling to 2048 points, an exponential filter corresponding to $1 \mathrm{~Hz}$ of line broadening, Fourier transformation, zero order phase, and automatic baseline corrections by polynomial interpolation. Spectra with a full width at half maximum smaller than $0.1 \mathrm{ppm}$ were included in the statistical analysis.

Quantification of MR spectroscopy measurements and calculation of metabolite concentrations were performed by using the internal-water reference method. ${ }^{35}$ Major metabolite peaks were assigned to $\mathrm{N}$-acetylaspartate (NAA) between 2.01 and $2.03 \mathrm{ppm}$, creatine $(\mathrm{Cr})$ between 3.01 and $3.03 \mathrm{ppm}$, and choline (Cho) between $3.21 \mathrm{ppm}$ and $3.23 \mathrm{ppm}$. Calculation of T2 values and T2-corrected signal-intensity peak areas for water-suppressed and unsuppressed spectra is an optimization problem that involves minimizing the squared error between the actual values of the measurement and the estimated function values evaluated at measurement points (MatLab; MathWorks, Natick, Mass). A monoexponential curve was fit to the metabolite peak area values. A double-exponential curve-fitting was performed for unsuppressed water spectra. CSF contamination was measured by using the difference in T2 decay between the brain tissue and CSF. The attenuation of brain tissue is accepted as $\rho=1.04 \mathrm{~kg} / \mathrm{L}$, and metabolite concentrations were calculated in millimoles per kilogram brain. $^{36}$

Study-specific phantom tests for calibration measurements and for testing the reproducibility of ${ }^{1} \mathrm{H}-\mathrm{MR}$ spectroscopy measurements were performed every week. In the phantom studies, we used a spheric phantom containing $0.1 \mathrm{~mol} / \mathrm{L} / \mathrm{L}$ sodium acetate and $0.1 \mathrm{~mol} / \mathrm{L} / \mathrm{L}$ lactate. We measured acetate concentration with the internal waterreference method by using the same TR and TE values. The variation in the measured acetate concentration in phantom studies was below $7 \%$.

\section{Statistical Analysis}

Statistical analyses of the results were performed by using SPSS 11.0 for Microsoft Windows (SPSS, Chicago, Ill). The differences in metabolite concentrations and $\mathrm{T} 2{ }_{\mathrm{B}}$ values between each patient and control group were investigated by analysis of variance. Correlation of metabolite concentrations with psychopathology scale scores was examined by using regression analysis. The relationship between metabolite concentrations and the duration of illness in chronic patients was assessed. Correlation between neurometabolite concentrations and DUP in first-episode patients was also tested. We also investigated the difference in metabolite concentrations between male and female patients by using the $t$ test. The Bonferroni correction was applied for multiple comparisons. In the analyses, a $P$ value of less than .05 was considered to indicate a statistically significant difference.

\section{Results}

All the spectra obtained from the patients and control subjects were deemed to be of good quality (Fig $2 A-D$ ). Moreover, the metabolite concentrations measured in the control subjects were consistent with the metabolite concentrations reported in previous studies. ${ }^{35,36}$ Clinical findings and demographic characteristics of the patients and their control subjects are presented in Table 1. There was no significant difference in the SANS and SAPS scores between the first-episode and chronic patients $(P>.05)$. An uncorrected comparison test revealed significantly higher BPRS scores in chronic patients than in first-episode patients. However, the significance was lost after correction for multiple comparisons $(P=.08)$.

Mean NAA concentration in all patients (first-episode and chronic patients together) was $8.91 \pm 0.84 \mathrm{mmol} / \mathrm{kg}$ brain, compared with a value of $10.40 \pm 0.44 \mathrm{mmol} / \mathrm{kg}$ brain in control subjects (Table 2). The difference in NAA concentrations 


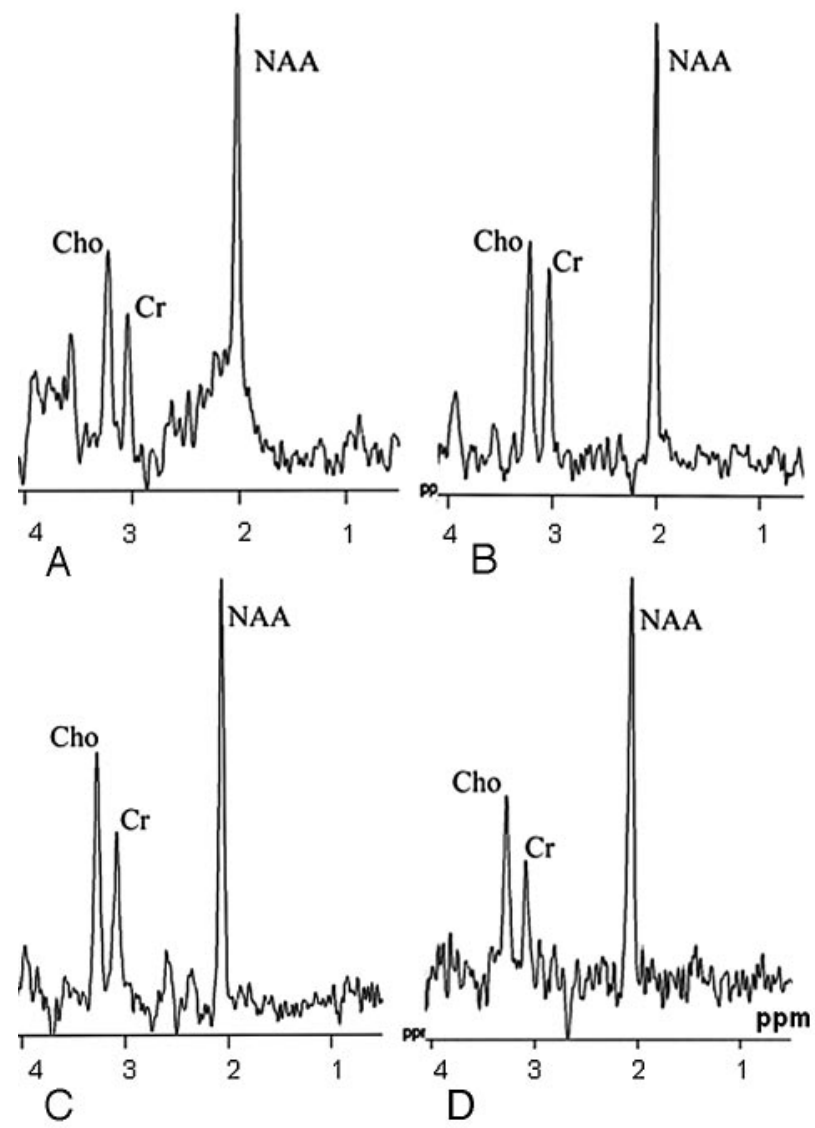

Fig 2. $A-D$, The proton MR spectra (STEAM, TR $=3.5$ seconds) obtained from a first-episode patient with different TE values (TE $=30,65,135$, and $300 \mathrm{~ms}$, respectively) show the major neurometabolite peaks (NAA at $2.02 \mathrm{ppm}, \mathrm{Cr}$ at $3.02 \mathrm{ppm}$, and Cho at 3.22 ppm).

between the patients and control subjects was statistically significant $(P<.001)$ (Fig 3). NAA concentration of all patients was negatively correlated with the BPRS $(r=-0.59, P=.001)$ and SANS scores $(r=-0.68, P<.001)$ (Fig $4 A,-B)$. The association of NAA concentrations with SAPS scores was also statistically significant $(r=-0.41, P=.028$; Fig $4 C)$.

In the first-episode patient group, the mean NAA concentration of patients was $8.97 \pm 0.82 \mathrm{mmol} / \mathrm{kg}$ brain, compared with a mean value of $10.41 \pm 0.45 \mathrm{mmol} / \mathrm{kg}$ brain in the respective control group (Table 2). The difference in NAA concentrations between the first-episode patient group and the respective control group was statistically significant $(P<$ $.001)$. In the chronic patient group, the mean NAA concentration of the patients was $8.86 \pm 0.89 \mathrm{mmol} / \mathrm{kg}$ brain, compared with a mean value of $10.40 \pm 0.44 \mathrm{mmol} / \mathrm{kg}$ brain in the respective control group $(P<.001)$. The difference between the NAA concentrations of the first-episode and chronic patient groups was not statistically significant $(P=.66)$. In the firstepisode patient group, the NAA concentrations of the patients were negatively correlated with the SANS $(r=-0.81, P=$ $.001)$ and BPRS $(r=-0.67, P=.025)$ scores. However, there was no correlation between the NAA concentrations and SAPS scores in the first-episode patient group $(r=-0.27, P=.39)$. On the other hand, the NAA concentrations of patients in the chronic patient group were significantly associated with BPRS $(r=-0.60, P=.014)$ and SANS $(r=-0.76, P=.001)$ scores.
Conversely, there was no relationship between the NAA concentrations and SAPS scores $(r=-0.34, P=.18)$ in this group. In addition, there was no significant association between the NAA concentrations and DUP values in the firstepisode patients $(r=-0.23, P=.47)$. The NAA concentrations of the chronic patients did not correlate with the duration of illness $(r=-0.03, P=.89)$.

$\mathrm{Cr}$ and Cho concentrations between first-episode and chronic patient groups and their respective control groups showed no significant difference $(P>.05)$ (Table 2). There was no relationship between both $\mathrm{Cr}$ and Cho concentrations and psychopathology scale scores $(P>.05)$. The $\mathrm{Cr}$ and Cho (Cr: $r=0.26, P=.31$; Cho: $r=0.26, P=.40$ ) concentrations did not correlate with the duration of illness in the chronic patients. There was no association between the $\mathrm{Cr}$ and Cho (Cr: $r=0.30, P=.33$; Cho: $r=0.25, P=.42$ ) concentrations and DUP in the first-episode patients. No sex predilection was noted for the metabolite concentrations $(P>.05)$.

The mean $\mathrm{T} 22_{\mathrm{B}}$ value of all patients was $77.23 \pm 11.97 \mathrm{~ms}$, compared with a mean value of $59.25 \pm 7.35 \mathrm{~ms}$ in the control subjects $(P<.001)$. The $\mathrm{T} 2{ }_{\mathrm{B}}$ values in both first-episode $(P<$ $.001)$ and chronic patient $(P<.001)$ groups also differed significantly from those of the respective control subjects. There was no significant difference in $\mathrm{T} 2{ }_{\mathrm{B}}$ values of first-episode and chronic patients $(P=.5)$. Likewise, no association between the $\mathrm{T} 2{ }_{\mathrm{B}}$ values and duration of illness was present in the chronic patients $(r=0.16, P=.55)$. The $\mathrm{T} 22_{\mathrm{B}}$ values did not correlate with the DUP in the first-episode patients $(r=0.28, P=.37)$. The $\mathrm{T} 2_{\mathrm{B}}$ values did not correlate with the psychopathology scale scores in any of the patient groups $(P>.05)$.

\section{Discussion}

Reciprocal and proper interaction of different cortical regions is required for information processing in the brain. Functional integration of spatially remote cognitive events is achieved by corticocortical connections. A disruption of corticocortical connections may lead to cognitive impairments. The disconnectivity theory involving the pathophysiology of schizophrenia is based on the hypothesis that an abnormality in cerebral cortical interconnections could cause or contribute to cognitive disturbances and symptoms of schizophrenia. ${ }^{2-4}$ Hoffman and McGlashan ${ }^{37}$ defined a neural network computer simulation model of reduced corticocortical connectivity in schizophrenia. Their simulation model could explain some of the positive psychotic symptoms of schizophrenia such as auditory hallucinations. The results of previous DTI and MR spectroscopy studies pointed to the presence of an axonal and/or a myelin-related pathology in schizophrenia. ${ }^{5-10,38}$ DTI measures diffusibility of water molecules in brain parenchyma. Dense packing of axonal fibers and myelination of axons decrease the diffusion rate of water molecules perpendicular to white matter tracts and leads to anisotropy. Thus, anisotropy reflects the structural integrity of axonal fibers and myelination. Pathologies causing demyelination or axonal loss may result in decreased anisotropy. The corpus callosum was found to be one of the common locations with reduced anisotropy in patients with schizophrenia. ${ }^{5-8}$ Because some of the structural studies selectively indicated abnormalities in the genu of the corpus callosum, we investigated the superior and posterior parts of the genu. ${ }^{5,17,25,26}$ Axonal fibers crossing the 


\begin{tabular}{|c|c|c|c|c|}
\hline \multirow[b]{2}{*}{ Subjects } & \multicolumn{3}{|c|}{ Metabolite Concentrations (mmol/kg brain) } & \multirow[b]{2}{*}{$\mathrm{T} 2_{\mathrm{B}}$ Values $(\mathrm{ms})$} \\
\hline & $N$-acetylaspartate & Creatine & Choline & \\
\hline \multicolumn{5}{|l|}{ First-episode group } \\
\hline Patients $(n=12)$ & $8.97 \pm 0.82$ & $3.63 \pm 0.23$ & $1.21 \pm 0.08$ & $76.17 \pm 12.26$ \\
\hline Controls $(n=14)$ & $10.41 \pm 0.45$ & $3.56 \pm 0.27$ & $1.18 \pm 0.07$ & $57.93 \pm 6.85$ \\
\hline Significance & $P<.001$ & $P=.54$ & $P=.39$ & $P<.001$ \\
\hline \multicolumn{5}{|l|}{ Chronic group } \\
\hline Patients $(n=16)$ & $8.86 \pm 0.89$ & $3.68 \pm 0.35$ & $1.22 \pm 0.09$ & $78.03 \pm 12.09$ \\
\hline Controls $(n=14)$ & $10.40 \pm 0.44$ & $3.72 \pm 0.25$ & $1.26 \pm 0.10$ & $60.57 \pm 7.85$ \\
\hline Significance & $P<.001$ & $P=.66$ & $P=.99$ & $P<.001$ \\
\hline \multicolumn{5}{|l|}{ Combined group } \\
\hline Patients $(n=28)$ & $8.91 \pm 0.84$ & $3.65 \pm 0.30$ & $1.24 \pm 0.11$ & $77.23 \pm 11.97$ \\
\hline Controls $(n=28)$ & $10.40 \pm 0.44$ & $3.64 \pm 0.27$ & $1.22 \pm 0.10$ & $59.25 \pm 7.35$ \\
\hline Significance & $P<.001$ & $P=.84$ & $P=.45$ & $P<.001$ \\
\hline
\end{tabular}

${ }^{*}$ Data are given as mean $\pm S D$.

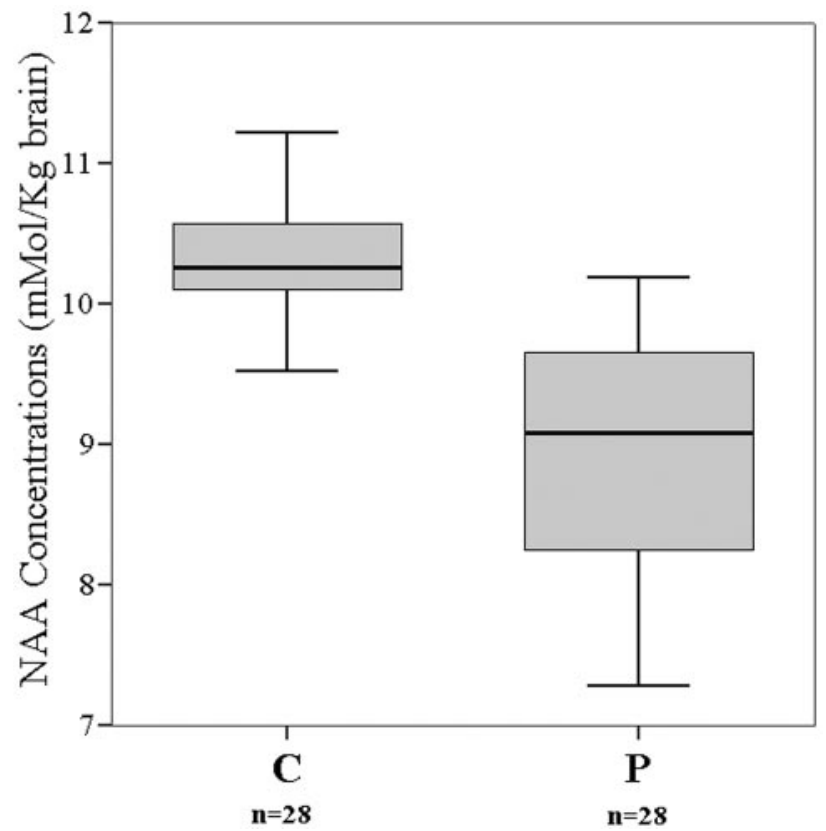

Fig 3. The box-plot graph demonstrates the distribution of NAA concentrations around the median values of all patients $(\mathrm{P})$ and of the control subjects $(\mathrm{C})$. The horizontal lines dividing the boxes represent the median values. The upper and lower edges of the boxes represent the upper and lower quartiles (medians of the upper and lower $50 \%$ of the values), respectively. The vertical lines (whiskers) are 1.5 times the inner quartile spread in length, which is measured from the median.

genu region of the corpus callosum connect frontal regions of cerebral hemispheres. Microstructural abnormality in the callosal fibers located in genu of the corpus callosum may lead to decreased interhemispheric connectivity and functional specialization in the frontal and temporal lobes, which have been suggested to occur in patients with schizophrenia. ${ }^{4}$

NAA is a free amino acid that is biosynthesized from acetyl coenzyme A aspartate by $\mathrm{D}$-aspartate $\mathrm{N}$-acetyltransferase in neuronal mitochondria. ${ }^{39}$ NAA is believed to be exclusively found in neurons and neuronal processes (axons and dendrites). Moreover, it is used as a marker of neuroaxonal integrity in ${ }^{1} \mathrm{H}$-MR spectroscopy studies. ${ }^{40}$ Pathologies that cause neuronal loss or impairment of neuroaxonal functions decrease NAA concentration. ${ }^{41}$ Likewise, neuroaxonal dysfunction, even without neuronal loss, may cause a reversible decrease in NAA concentration. ${ }^{42}$ On the contrary, increased neuronal activity in both physiologic and pathologic conditions may cause an increase in NAA concentration. ${ }^{43,44}$ Thus, neuroaxonal activity-dependent changes in NAA concentration demonstrate a close relationship between neuroaxonal functional status and NAA. Decreased NAA concentration in the corpus callosum in our patients may be due to decreased axonal attenuation, axonal dysfunction, or both. Histologic studies conducted to investigate the corpus callosum of patients with schizophrenia revealed controversial results. ${ }^{45,46}$ Although most of them showed no difference between patients and control subjects, Highley et $\mathrm{al}^{34}$ reported a significant sex-specific decrease in both the cross-sectional area and axonal fiber attenuation of the corpus callosum favoring female schizophrenics. No sex predilection was noted for the metabolite concentrations in our study. The correlation between decreased NAA concentration and severity of psychotic symptoms suggests that the pathology causing a decrease in callosal NAA concentration plays a role in the pathophysiology of schizophrenia.

Schizophrenia is accepted as a genetically mediated neurodevelopmental disease. ${ }^{47}$ The neurodevelopmental theory of schizophrenia states that genetically mediated pathogenetic factors, long before the onset of formal psychotic symptoms, lead to abnormal changes in the normal course of neurodevelopment, resulting in subtle abnormalities in neurons and neural circuits. The early presentation of cognitive dysfunctions before the onset of psychotic symptoms supports the neurodevelopment theory. The difference in NAA concentrations between first-episode and chronic patients was not significant in our study. This finding shows that the pathology leading to decreased NAA concentration in the corpus callosum is present at the beginning of illness. Furthermore, the lack of a relationship between NAA concentrations and the duration of illness suggests that neuroaxonal pathology leading to the decreased NAA concentration is not a progressive process during the clinical course of schizophrenia.

Pure myelin-related pathologies may cause a decrease in NAA concentration at ${ }^{1} \mathrm{H}-\mathrm{MR}$ spectroscopy. ${ }^{41}$ Decreased callosal NAA concentration observed in our patients may result from a myelin-related pathology or oligodendrocyte dysfunction. Histologic studies suggesting the presence of a myelinrelated pathology or oligodendrocyte dysfunction in schizophrenia are present in the English literature. ${ }^{48-51}$ In an electron 

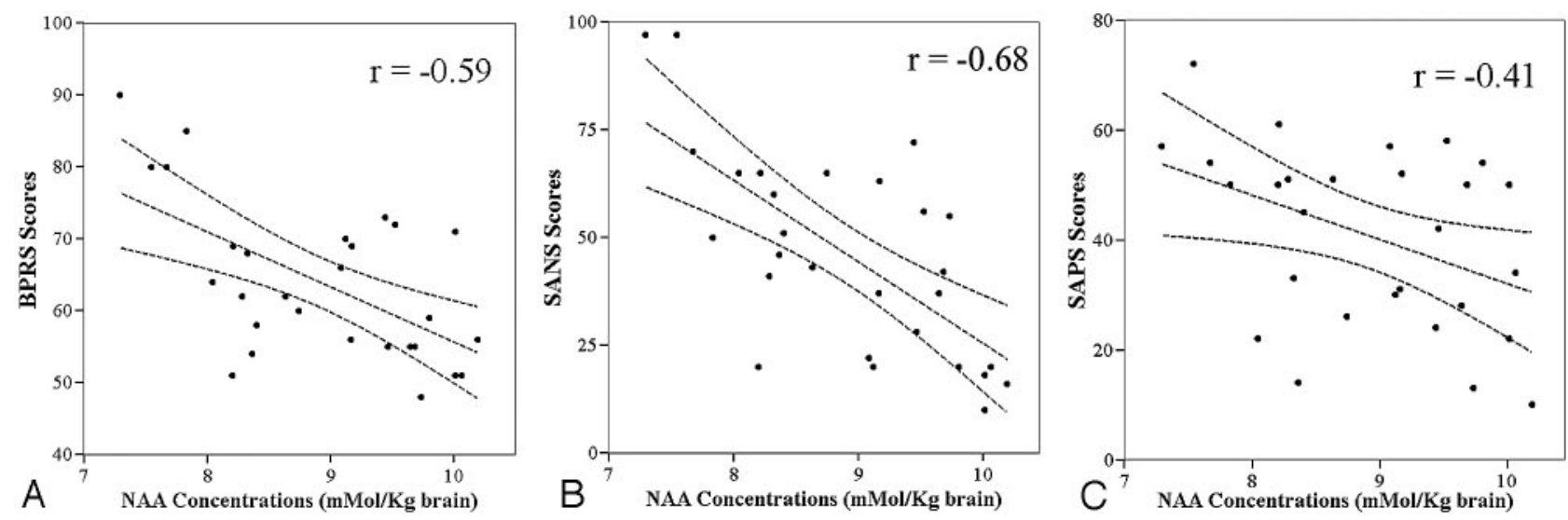

Fig 4. $A-C$, The scatter plots show the relationships between the NAA concentrations (mmol/kg brain) of all patients and the severity of symptoms. The lines between the $95 \%$ confidence curves represent linear regression lines. $A$, The negative correlation between the NAA concentrations and BPRS scores $(r=-0.59, P=.001)$. $B$, The relationship between the NAA concentrations and severity of negative symptoms (SANS scores) $(r=-0.68, P<.001)$. $C$, The association $(r=-0.41, P=.028)$ of NAA concentrations with the severity of positive symptoms (SAPS scores).

microscopic study, ultrastructural changes, necrosis of oligodendrocytes, and damage of myelin lamellae were reported. ${ }^{49}$ A decrease in attenuation of oligodendrocytes in the frontal cortex of patients with schizophrenia was found in another postmortem study. ${ }^{48}$ The gene expression analyses revealed differential expression of myelination-related genes, suggesting a disruption in oligodendrocyte function in schizophrenia. ${ }^{11,12,51} \mathrm{~A}$ link between schizophrenia and the reduced expression of $2^{\prime}, 3^{\prime}$-cyclic nucleotide $3^{\prime}$-phosphodiesterase gene, a marker of myelin forming cells, has been demonstrated in a recent study. ${ }^{51}$ Oligodendrocytes and myelin increase neuronal conduction velocity by their insulating properties and provide extrinsic support for axons. Myelin-related pathologies impair neuroaxonal conduction in white matter tracts and consequently cause corticocortical disconnections. Metachromatic leukodystrophy, for instance, is a dysmyelinating metabolic white matter disease, which demonstrates the pathophysiologic linkage between corticocortical disconnection and psychotic symptoms. ${ }^{52}$ Patients with adult-onset metachromatic leukodystrophy frequently present psychotic symptoms. Similarly, a myelin-related pathology causing reduced corticocortical connectivity may lead to the symptoms of schizophrenia.

Pure water has a T2 relaxation time of around 3 seconds. Owing to an interaction of water molecules with nonaqueous molecules in brain parenchyma, the $\mathrm{T} 2$ relaxation time of brain $\mathrm{T} 2_{\mathrm{B}}$ is much shorter. In brain parenchyma, myelin-water, intracellular/extracellular water, and CSF contribute to $\mathrm{T} 2{ }_{\mathrm{B}} \cdot{ }^{53}$ Intra- and extracellular water constitutes the major tissue-water fraction in brain and has a T2 relaxation time of approximately $80-100 \mathrm{~ms}$. Water molecules trapped between myelin bilayers (myelin water) constitute a smaller fraction of tissue water and have a shorter $\mathrm{T} 2$ relaxation time (approximately $20 \mathrm{~ms}$ ) than intra- and extracellular water and CSF. Because water trapped between myelin bilayers is proportional to the myelin content of the tissue, $\mathrm{T} 2_{\mathrm{B}}$ can provide indirect measurement of the myelin content of this tissue. Demyelinating diseases decrease the myelin water fraction and prolong the $\mathrm{T} 22_{\mathrm{B}}$ value. In our study, the $\mathrm{T} 2_{\mathrm{B}}$ values in patients were significantly prolonged compared with those of control subjects. A myelin-related pathology or decrease in axonal at- tenuation may be the cause of prolonged $\mathrm{T} 2{ }_{\mathrm{B}}$ in our patients. Theoretically, any factor or pathology that is able to alter the intrinsic magnetic field within tissue may change T2 relaxation times. Prolonged T2 relaxation time in the genu of the corpus callosum was reported in a recent MR imaging study of patients with schizophrenia. ${ }^{54} \mathrm{~T} 2$ relaxation times in the frontal white matter of patients with schizophrenia was also prolonged. ${ }^{53}$ In these studies, the authors proposed that decrease in the myelin water fraction might be the cause of prolonged $\mathrm{T} 2$ relaxation times. In our study, the accompaniment of a prolonged $\mathrm{T} 2_{\mathrm{B}}$ value with reduced NAA concentration suggests the presence of an axonal or myelin-related pathology in the corpus callosum in patients with schizophrenia. A prolonged $\mathrm{T} 2 \mathrm{~B}_{\mathrm{B}}$ value was associated neither with the duration of illness nor with the severity of psychopathology in our study. This finding is consistent with the possibility that the pathology altering the $\mathrm{T} 2_{\mathrm{B}}$ value has a neurodevelopmental basis.

Phosphorylcholine and glycerophosphorylcholine, which are the precursors of cell membrane synthesis and the breakdown products of myelin and cell membrane, contribute to Cho peak at proton MR spectra. ${ }^{40}$ The lack of difference in Cho concentration between the patients and control subjects showed that there was no active demyelination ongoing in the corpus callosum of the patients with schizophrenia.

All of our patients were in the acute phase of illness. Therefore, all the patients except 2 were under antipsychotic treatment during the ${ }^{1} \mathrm{H}-\mathrm{MR}$ spectroscopy examinations. Due to ethical considerations, we could not increase the number of drug-naive patients to compare metabolite concentrations of antipsychotic-naive patients and the patients under antipsychotic treatment. Hence, we could not exclude the potential effect of antipsychotic drugs on neurometabolite concentrations. This may be accepted as a limitation of our study. However, lack of a difference in NAA concentrations between the first-episode and chronic patients demonstrated that chronic antipsychotic treatment did not lower the NAA concentration in the corpus callosum of the patients. There are controversial results in the previous literature involving the effect of antipsychotic drugs on NAA concentration. In one of the longitudinal ${ }^{1} \mathrm{H}$-MR spectroscopy studies, Bertolino et $\mathrm{al}^{55}$ reported an elevation of $\mathrm{NAA} / \mathrm{Cr}$ ratio in response to antipsychotic 
medication. However, this finding could not be confirmed in the other studies. In addition, recently reported animal studies have shown that antipsychotic medication does not alter neurometabolite concentrations measured by ${ }^{1} \mathrm{H}-\mathrm{MR}$ spectroscopy. ${ }^{56}$

In conclusion, the prolonged $\mathrm{T} 2$ relaxation time of tissue water in the corpus callosum and the correlation of decreased NAA concentration with the severity of psychopathology are the outstanding findings of this study. Finally, our results support the previously proposed callosal disconnection theory in schizophrenia.

\section{References}

1. Wernicke C. Grundrisse der Psychiatrie. Leipzig, Germany: Thieme; 1906

2. Stephan KE, Baldeweg T, Friston KJ. Synaptic plasticity and dysconnection in schizophrenia. Biol Psychiatry 2006;59:929-39. Epub 2006 Jan 19

3. Friston KJ. The disconnection hypothesis. Schizophr Res 1998;30:115-25

4. Crow TJ. Schizophrenia as a transcallosal misconnection syndrome. Schizophr Res 1998;30:111-14

5. Lim KO, Hedehus M, Moseley M, et al. Compromised white matter tract integrity in schizophrenia inferred from diffusion tensor imaging. Arch Gen Psychiatry 1999;56:367-74

6. Park HJ, Westin CF, Kubicki M, et al. White matter hemisphere asymmetries in healthy subjects and in schizophrenia: a diffusion tensor MRI study. $\mathrm{Neu}$ roimage 2004;23:213-23

7. Kanaan RA, Kim JS, Kaufmann WE, et al. Diffusion tensor imaging in schizophrenia. Biol Psychiatry 2005;58:921-29. Epub 2005 Jul 25

8. Buchsbaum MS, Friedman J, Buchsbaum BR, et al. Diffusion tensor imaging in schizophrenia. Biol Psychiatry 2006;60:1181-87. Epub 2006 Aug 7

9. Foong J, Maier M, Barker GJ, et al. In vivo investigation of white matter pathology in schizophrenia with magnetization transfer imaging. J Neurol Neurosurg Psychiatry 2000;68:70-74

10. Foong J, Symms MR, Barker GJ, et al. Neuropathological abnormalities in schizophrenia: evidence from magnetization transfer imaging. Brain 2001;124:882-92

11. Hakak Y, Walker JR, Li C, et al. Genome-wide expression analysis reveals dysregulation of myelination-related genes in chronic schizophrenia. Proc Natl Acad Sci U S A 2001;98:4746-51

12. Iwamoto K, Bundo M, Yamada K, et al. DNA Methylation status of SOX 10 correlates with its downregulation and oligodendrocyte dysfunction in schizophrenia. J Neurosci 2005;25:5376-81

13. Gazzaniga MS. Cerebral specialization and interhemispheric communication: does the corpus callosum enable the human condition. Brain 2000;123:1293-326

14. Crow TJ, Ball J, Bloom SR, et al. Schizophrenia as an anomaly of development of cerebral asymmetry: a postmortem study and a proposal concerning the genetic basis of the disease. Arch Gen Psychiatry 1989;46:1145-50

15. DeLisi LE, Sakuma M, Kushner M, et al. Anomalous cerebral asymmetry and language processing in schizophrenia. Schizophr Bull 1997;23:255-71

16. Downhill JE, Buchsbaum MS, Wei T, et al. Shape and size of the corpus callosum in schizophrenia and schizotypal personality disorder. Schizophr Res 2000;42:193-208

17. Keshavan MS, Diwadkar VA, Harenski K, et al. Abnormalities of the corpus callosum in first episode, treatment naive schizophrenia. J Neurol Neurosurg Psychiatry 2002;72:757-60

18. Rosenthal R, Bigelow LB. Quantitative brain measurements in chronic schizophrenia. Br J Psychiatry 1972;121:259-64

19. Nasrallah HA, Andreasen NC, Coffman JA, et al. A controlled magnetic resonance imaging study of corpus callosum thickness in schizophrenia. Biol Psychiatry 1986;21:274-82

20. Casanova MF, Sanders RD, Goldberg TE, et al. Morphometry of the corpus callosum in monozygotic twins discordant for schizophrenia: a magnetic resonance imaging study. J Neurol Neurosurg Psychiatry 1990;53:416-21

21. Woodruff PW, McManus IC, David AS. Meta-analysis of corpus callosum size in schizophrenia. J Neuro Neurosurg Psychiatry 1995;58:457-61

22. Casanova MF, Zito M, Goldberg TE, et al. Corpus callosum curvature in schizophrenic twins. Biol Psychiatry 1990;28:83-84

23. Narr KL, Thompson PM, Sharma T, et al. Mapping morphology of the corpus callosum in schizophrenia. Cereb Cortex 2000;10:40-49

24. Frumin M, Golland P, Kikinis R, et al. Shape differences in the corpus callosum in first-episode schizophrenia and first-episode psychotic affective disorder. Am J Psychiatry 2002;159:866-68

25. Hulshoff Pol HE, Schnack HG, Mandl RC, et al. Focal white matter density changes in schizophrenia: reduced inter-hemispheric connectivity. Neuroimage 2004;21:27-35

26. Diwadkar VA, DeBellis MD, Sweeney JA, et al. Abnormalities in MRI-mea- sured signal intensity in the corpus callosum in schizophrenia. Schizophr Res 2004;67:277-82

27. Steel RM, Bastin ME, McConnell S, et al. Diffusion tensor imaging (DTI) and proton magnetic resonance spectroscopy (1H MRS) in schizophrenic subjects and normal controls. Psychiatry Res 2001;106:161-70

28. First MB, Spitzer RL, Gibbon M, et al. Structured Clinical Interview for DSM-IV Axis I disorders (SCID-I), Clinical Version. Washington, DC; American Psychiatric Press; 1997

29. Pinals D, Malhotra A, Breier A. Informed consent in schizophrenia research. Psychitar Serv 1998;49:244

30. Lukoff D, Nuechterlien K, Ventura A. Manual for the expanded brief psychiatric rating scale. Schizophr Bull 1986;12:594-602

31. Andreasen NC. The Scale for the Assessment of Positive Symptoms (SAPS). Iowa City, Iowa; University of Iowa; 1984

32. Andreasen NC. The Scale for the Assessment of Negative Symptoms (SANS). Iowa City, Iowa; University of Iowa; 1983

33. Witelson SF. Hand and sex differences in the isthmus and genu of the human corpus callosum. Brain 1989;112:799-835

34. Highley JR, Esiri MM, McDonald B, et al. The size and fibre composition of the corpus callosum with respect to gender and schizophrenia: a post-mortem study. Brain 1999;122:99-110

35. Keevil SF, Barbiroli B, Brooks JC, et al. Absolute metabolite quantification by in vivo NMR spectroscopy. II. A multicenter trial of protocols for in vivo localised proton studies of human brain. Magn Reson Imaging 1998;16:1093-106

36. Michaelis T, Merboldt KD, Bruhn H, et al. Absolute concentrations of metabolites in the adult human brain in vivo: quantification of localized proton MR spectra. Radiology 1993;187:219-27

37. Hoffman RE, McGlashan TH. Reduced corticocortical connectivity can induce perception pathology and hallucinated voices. Schizophr Res 1998;30:137-41

38. Steen RG, Hamer RM, Lieberman JA. Measurement of brain metabolites by $1 \mathbf{H}$ magnetic resonance spectroscopy in patients with schizophrenia: a systematic review and meta-analysis. Neuropsychopharmacology 2005;30:1949-62

39. Neale JH, Bzdega T, Wroblewska B. N-Acetylaspartylglutamate: the most abundant peptide neurotransmitter in the mammalian central nervous system. J Neurochem 2000;75:443-52

40. Miller BL. A review of chemical issues in H NMR spectroscopy: N-acetyl-Laspartate, creatine and choline. NMR Biomed 1991;4:47-52

41. Brandao LA, Domingues RC. MR Spectroscopy of the Brain. Philadelphia: Lippincott, Williams \& Wilkins; 2004:17-128

42. Lentz MR, Kim JP, Westmoreland SV, et al. Quantitative neuropathologic correlates of changes in ratio of $\mathrm{N}$-acetylaspartate to creatine in macaque brain. Radiology 2005;235:461-68

43. Najm IM, Wang Y, Shedid D, et al. MRS metabolic markers of seizures and seizure-induced neuronal damage. Epilepsia 1998;39:244-50

44. Aydin K, Ciftci K, Terzibasioglu E, et al. Quantitative proton MR spectroscopic findings of cortical reorganization in the auditory cortex of musicians. AJNR Am J Neuroradiol 2005;26:128-36

45. Nasrallah HA, Mccalley-Whitters M, Bigelow LB, et al. A histological study of the corpus callosum in chronic schizophrenia. Psychiatry Res 1983;8:251-60

46. Casanova MF, Zito M, Bigelow LB, et al. Axonal counts of the corpus callosum of schizophrenic patients. J Neuropsychiatry Clin Neurosci 1989;1:391-93

47. Lieberman JA, Perkins D, Belger A, et al. The early stages of schizophrenia: speculations on pathogenesis, pathophysiology, and therapeutic approaches. Biol Psychiatry 2001;50:884-97

48. Uranova NA, Vostrikov VM, Orlovskaya DD, et al. Oligodendroglial density in the prefrontal cortex in schizophrenia and mood disorders: a study from the Stanley Neuropathology Consortium. Schizophr Res 2004;67:269-75

49. Uranova N, Orlovskaya D, Vikhreva O, et al. Electron microscopy of oligodendroglia in severe mental illness. Brain Res Bull 2001;55:597-610

50. Hof PR, Haroutunian V, Copland C, et al. Molecular and cellular evidence for an oligodendrocyte abnormality in schizophrenia. Neurochem Res 2002;27:1193-200

51. Peirce TR, Bray NJ, Williams NM, et al. Convergent evidence for $2^{\prime}, 3^{\prime}$-cyclic nucleotide $3^{\prime}$-phosphodiesterase as a possible susceptibility gene for schizophrenia. Arch Gen Psychiatry 2006;63:18-24

52. Hyde TM, Ziegler JC, Weinberger DR. Psychiatric disturbances in metachromatic leukodystrophy: insights into the neurobiology of psychosis. Arch Neurol 1993;50:401-06

53. MacKay A, Laule C, Vavasour I, et al. Insights into brain microstructure from the T2 distribution. Mag Reson Imaging 2006;24:515-25

54. Flynn SW, Lang DJ, Mackay AL, et al. Abnormalities of myelination in schizophrenia detected in vivo with MRI, and post-mortem with analysis of oligodendrocyte proteins. Mol Psychiatry 2003;8:811-20

55. Bertolino A, Callicott JH, Mattay VS, et al. The effect of treatment with antipsychotic drugs on brain $\mathrm{N}$-acetylaspartate measures in patients with schizophrenia. Biol Psychiatry 2001;49:39-46

56. Bustillo J, Wolff C, Myers-y-Gutierrez A, et al. Treatment of rats with antipsychotic drugs: lack of an effect on brain $\mathrm{N}$-acetyl aspartate levels. Schizophr Res 2004;66:31-39 